\title{
LEVAN FROM BACILLUS SUBTILIS NATTO: ITS EFFECTS IN NORMAL AND IN STREPTOZOTOCIN-DIABETIC RATS
}

\section{Fernando Cesar Bazani Cabral de Melo ${ }^{1}$, Cássia Thaïs Bussamra Viera Zaia ${ }^{2}$, Maria Antonia Pedrine Colabone Celligoi ${ }^{*}$}

${ }^{1}$ Departamento de Bioquímica e Biotecnologia Centro de Ciências Exatas, Universidade Estadual de Londrina, Londrina, PR, Brasil; ${ }^{2}$ Departamento de Ciências Fisiológicas, Centro de Ciências Biológicas, Universidade Estadual de Londrina, Londrina, PR, Brasil.

Submitted: July 14, 2011; Returned to authors for corrections: January 10, 2012; Approved: June 07, 2012.

\begin{abstract}
Levan is an exopolysaccharide of fructose primarily linked by $\beta-(2 \rightarrow 6)$ glycosidic bonds with some $\beta$ $(2 \rightarrow 1)$ branched chains. Due to its chemical properties, levan has possible applications in both the food and pharmaceutical industries. Bacillus subtilis is a promising industrial levan producer, as it ferments sucrose and has a high levan-formation capacity. A new strain of B. subtilis was recently isolated from Japanese food natto, and it has produced levan in large quantities. For future pharmaceutical applications, this study aimed to investigate the effects of levan produced by B. subtilis Natto, mainly as potential hypoglycemic agent, (previously optimized with a molecular weight equal to 72.37 and $4,146 \mathrm{kDa}$ ) in Wistar male rats with diabetes induced by streptozotocin and non-diabetic rats and to monitor their plasma cholesterol and triacylglycerol levels. After 15 days of experimentation, the animals were sacrificed, and their blood samples were analyzed. The results, compared using analysis of variance, demonstrated that for this type of levan, a hypoglycemic effect was not observed, as there was no improvement of diabetes symptoms during the experiment. However, levan did not affect any studied parameters in normal rats, indicating that the exopolysaccharide can be used for other purposes.
\end{abstract}

Key words: Levan, Bacillus subtilis Natto, hypoglycemia.

\section{INTRODUCTION}

Diabetes mellitus is a chronic disease with an increasingly growing incidence rate, leading to a high number of deaths. In addition to resulting in an increased plasma glucose level (34), diabetes results in an increase in the level of cholesterol (31), facilitating the development of cardiovascular disease (28). According to the World Health Organization (WHO) (29), more than 220 million people worldwide have diabetes. In 2004, an estimated 3.4 million people died from complications associated with diabetes. In 2008, diabetes was the underlying cause of 1.3 million deaths, and the global prevalence was estimated to be $9 \%$. The WHO projects that diabetes deaths will double between 2005 and 2030, and the estimated costs in China alone will be US\$558 billion in lost national income between the years 2006 and 2015 due to heart disease, stroke 
and diabetes alone.

Many of the currently marketed drugs have several side effects and limitations (14), which makes it necessary to study alternatives to these drugs. Recently, many natural and nontoxic polysaccharides isolated from bacteria, fungi and plants with potential applications against diabetes have been studied, including levan (4, 13, 30), oligosaccharide ROS (33), heteropolysaccharide protein (12), heteropolysaccharide CSP-1 (15), botryosphaeran (21) heteropolysaccharide PPSB (27), chitosan $(17,31)$ and acid polysaccharide LBP-1 (34).

Levan is an exopolysaccharide composed of fructose that is primarily linked by $\beta-(2 \rightarrow 6)$ glycosidic bonds with some $\beta$ $(2 \rightarrow 1)$ branch chains (11). It is synthesized by levansucrase (EC 2.4.1.10) in medium with a large quantity of sucrose (20). Levan presents a number of benefits that can be exploited, especially in the pharmaceutical industry, such as a hypoglycemic, hypocholesterolemic and anticarcinogenic agent; a blood plasma substitute; and an immunomodulator, immunostimulatory and anti-cytotoxic agent (1, 3, 4, 10, 22, $26,32)$.

Among the microorganisms capable of synthesizing levan, Bacillus subtilis Natto, a nonpathogenic strain (23) that is used in the fermentation of Japanese food natto, has demonstrated great potential in converting sucrose into levan $(24,25)$.

Because levan is an easily accessible, non-toxic polymer with pharmaceutical potential, this study aimed to investigate the effects of levan produced by Bacillus subtilis Natto, mainly as potential hypoglycemic agent, in normal rats and with diabetes mellitus induced by a streptozotocin-diabetogenic drug.

\section{MATERIALS AND METHODS}

\section{Microorganism and culture media}

The B. subtilis Natto strain was isolated from the Japanese food natto by the Department of Biochemistry and Biotechnology, and it was identified by the Tropical Culture Collection, André Tosselo Foundation, Campinas SP, Brazil.
The strain was sub-cultured every 2 months and maintained at $4{ }^{\circ} \mathrm{C}$ in a medium containing 50 g.L $\mathrm{L}^{-1}$ peptone, 30 g.L ${ }^{-1}$ meat extract and 20 g. $\mathrm{L}^{-1}$ agar. The inoculum medium contained 100 g.L ${ }^{-1}$ sucrose, 2 g.L ${ }^{-1}$ yeast extract, 2 g.L $\mathrm{LH}_{2}^{-1} \mathrm{PO}_{4}, 1$ g.L $\mathrm{L}^{-1}$ $\left(\mathrm{NH}_{4}\right)_{2} \mathrm{SO}_{4}$ and 0.5 g. $\mathrm{L}^{-1} \mathrm{MgSO}_{4} \cdot 7 \mathrm{H}_{2} \mathrm{O}$ (4). The fermentation medium contained 300 g.L $\mathrm{L}^{-1}$ sucrose, 2 g.L $\mathrm{L}^{-1}$ yeast extract, 1 g. $\mathrm{L}^{-1} \mathrm{KH}_{2} \mathrm{PO}_{4}, 3$ g. $\mathrm{L}^{-1}\left(\mathrm{NH}_{4}\right)_{2} \mathrm{SO}_{4}, 0.6$ g. $\mathrm{L}^{-1} \mathrm{MgSO}_{4} \cdot 7 \mathrm{H}_{2} \mathrm{O}, 0.2$ g.L $\mathrm{L}^{-1} \mathrm{MnSO}_{4}$ and 0.25 g.L. $\mathrm{L}^{-1}$ ammonium citrate (9, modify).

\section{Levan production}

The levan used in these experiments was produced by submerged fermentation, and its production conditions were previously optimized by statistical planning (19). The best productivity was obtained at 300 g. $\mathrm{L}^{-1}$ of sucrose, $\mathrm{pH} 8$, with a temperature of $39.5^{\circ} \mathrm{C}$ and a shaking speed of $100 \mathrm{rpm}$ for 21 hours, which corresponded to $5.82 \mathrm{~g} \mathrm{~L}^{-1} \mathrm{~h}^{-1}$ when using the fermentation medium described in the previous section. Levan obtained in optimized conditions was characterized by HighPerformance Size Exclusion Chromatography (HPSEC). Two components were detected: peak 1 corresponded to a molecular weight of $4,146 \mathrm{kDa}$, which was equivalent to $5 \%$ of the sample, and peak 2 corresponded to $72.37 \mathrm{kDa}$, which was the majority component equivalent to $95 \%$ of the sample. To test its use as a hypoglycemic agent, levan was produced by fermentation on a larger scale using a 2000-mL Erlenmeyer flask with $500 \mathrm{ml}$ of culture medium. The levan obtained was precipitated with absolute ethanol, dialyzed against deionized water, lyophilized and stored.

\section{Preparation of levan solution}

A solution of levan was prepared at $200 \mathrm{mg} \cdot \mathrm{kg}^{-1}$ of animal body weight $(32,5)$ in distilled water. The solution was subjected to flowing steam for $20 \mathrm{~min}$, and after cooling, it was transferred to sterile containers for subsequent application.

\section{Experimental animals}

This work was conducted at the Department of Physiological Sciences (CIF) at the Center of Biological 
Sciences (CCB) in the State University of Londrina (UEL), and all experiments were approved by the Ethics Committee on Animal Experiments of UEL (EAEC - UEL) $n^{\circ}$. 7/10, process $n^{\circ} .1171 /$ 2010-08.

The animals were obtained from the Central Animal Vivarium at the State University of Londrina, Paraná, Brazil, and housed in 4 collective cages with controlled temperature and humidity $\left(23 \pm 2{ }^{\circ} \mathrm{C}\right.$ and $\left.60 \pm 5 \%\right)$ and a 12-h light:12-h dark cycle. They were given free access to water and food (Nivulab CR1, Nuvital ${ }^{\circledR}$ - Apucarana, PR-Brazil). After one week, the animals were transferred to individual cages and randomly separated into 4 groups with five animals in each group: normal $(\mathrm{N})$, normal + levan $(\mathrm{N}+\mathrm{Lev})$, diabetic (D) and diabetic + levan $(\mathrm{D}+\mathrm{Lev})$. All of the environmental conditions were maintained during the experimental period.

The levan solution was administered by gavage to the groups $(\mathrm{N}+\mathrm{Lev})$ and $(\mathrm{D}+\mathrm{Lev})$ at a dose of $200 \mathrm{mg} \cdot \mathrm{kg}^{-1}$ body weight daily for 15 days, while groups (N) and (D) received distilled water. Weight gain, food intake measured in grams of food consumed per $100 \mathrm{~g}$ of body weight $\left(\mathrm{g} .100 \mathrm{~g}^{-1}\right)$, and the rate of feed conversion efficiency (FCE) (the mass of the food eaten divided by the body mass gain) were analyzed over the 15 days of experimentation.

\section{Preparation of diabetic rats}

The rats were fasted for $12 \mathrm{~h}$, and diabetes was induced by an i.m. injection of streptozotocin (STZ) (Sigma Chemical Co.) in a single dose of $65 \mathrm{mg} . \mathrm{kg}^{-1}$ body weight. The drug was dissolved in a freshly prepared $0.1 \mathrm{M}$ citrate buffer $(\mathrm{pH} 4.5)$ according to Bolkent et al. (2). The normal animals, $(\mathrm{N})$ and $(\mathrm{N}+\mathrm{Lev})$, received only citrate buffer. Two days after STZ injection, the glucose level in the urine was determined with a glucose oxidase assay, and the animals that had a value above $250 \mathrm{mg} \cdot \mathrm{dL}^{-1}$ were considered diabetic.
The diabetic rats used in this work, those in groups (D) and $(\mathrm{D}+\mathrm{Lev})$, were induced by the action of STZ, a broad-spectrum antibiotic originated from Streptomyces acromogenes, which destroys pancreatic $\beta$-cells, preventing the production of insulin and resulting in increased blood glucose concentration characteristic of type I diabetes (12). Therefore, the drug's action prevents the recovery of the animals, and symptom improvement is observed only during treatment with compounds that can promote the reduction of metabolic disorders.

\section{Evaluation of glucose, total cholesterol and triacylglycerol levels}

After the last day of treatment (16th), the animals were fasted for $16 \mathrm{~h}$ and then sacrificed by decapitation. Blood was collected in heparinized tubes (Liquemine $5000 \mathrm{IU}$ ) and centrifuged at 7000 $\mathrm{G}$ for $30 \mathrm{~min}$ to separate the plasma. Immediately after centrifugation, plasma measurements were performed using the oxidase/peroxidase method with commercial kits (Biodiagnóstica ${ }^{\circledR}$, PR) for glucose (Glucose Bioliquid), total cholesterol (Cholesterol Bioliquid) and triglyceride (Triglycerides Bioliquid) levels to evaluate the hypoglycemic activity of levan.

\section{Statistical analysis}

All values are expressed as the mean \pm standard deviation (S.D.). Statistical significance was calculated by analysis of variance (ANOVA) followed by Student's t-test. $\mathrm{P}<0.05$ was considered statistically significant.

\section{RESULTS AND DISCUSSION}

\section{Analysis of glucose, total cholesterol and triacylglycerol levels in fasting blood}

After fifteen days of experimentation, the levels of plasma glucose, total cholesterol and triacylglycerol were measured, and the results are shown in Table 1.

Table 1. Plasma concentration of glucose, total cholesterol and triglycerides in normal $(\mathrm{N})$, normal + levan $(\mathrm{N}+\mathrm{Lev})$, diabetic (D) and diabetic + levan (D+Lev) rats after fifteen days of treatment.

\begin{tabular}{|c|c|c|c|}
\hline Groups & Glucose (mg.dL $\left.{ }^{-1}\right)$ & Total Cholesterol (mg.dL $\left.{ }^{-1}\right)$ & Triacylglycerol (mg.dL ${ }^{-1}$ ) \\
\hline $\mathrm{N}$ & $111.64 \pm 10.21^{(\mathrm{a})}$ & $86.83 \pm 18.87^{(\mathrm{a})}$ & $100.03 \pm 9.21^{(\mathrm{a})}$ \\
\hline $\mathrm{N}+$ Lev & $116.11 \pm 1.21^{(\mathrm{a})}$ & $84.59 \pm 11.57^{(\mathrm{a})}$ & $84.61 \pm 25.63^{(\mathrm{a})}$ \\
\hline $\mathrm{D}$ & $434.75 \pm 42.08^{(b)}$ & $86.79 \pm 16.69^{(a)}$ & $564.87 \pm 480.14^{(\mathrm{ab})}$ \\
\hline $\mathrm{D}+\mathrm{Lev}$ & $437.88 \pm 74.14^{(\mathrm{b})}$ & $115.45 \pm 23.60^{(\mathrm{a})}$ & $1,085.91 \pm 407.14^{(\mathrm{b})}$ \\
\hline
\end{tabular}


The plasma glucose values observed in groups $(\mathrm{N})$ and $(\mathrm{N}+\mathrm{Lev})$ did not differ statistically. Likewise, no difference was observed for the glucose level between the (D) and (D+Lev) groups. Based on these results, we can state that the levan produced by $B$. subtilis Natto used in this work did not act as a hypoglycemic agent because it did not reduce the glucose level of group (D+Lev) compared with group (D).

The total cholesterol levels did not differ statistically among the groups. The triacylglycerol level was significantly different between normal and diabetics rats, but within the groups, it was not different, as the standard deviation was in the same range, suggesting that the levan applied had neither hypocholesterolemic nor hypolipidemic effects. Although the statistical data show no difference between diabetic groups, the polymer unexpectedly increased the triacylglycerol levels in the $(\mathrm{D}+\mathrm{Lev})$ group. Therefore, the data obtained in this study do not agree with the results published by Yamamoto et al. (30), in which, despite the hypercaloric diet, they observed reductions in the levels of plasma cholesterol, triacylglycerol and glucose of $40 \%, 5 \%$ and $10 \%$, respectively, when using a 1 or $5 \%$ composition of high-molecular weight levan $(2000 \mathrm{kDa})$ in the feed they offered. These authors proposed that a possible unknown mechanism of entrapping sterols molecules by levan could lead to this lowering of cholesterol and triacylglycerol levels.

Kang et al. (13), using high-molecular weight levan at a concentration of 1,5 and $10 \%$ in diets for obese rats, observed that levan acted as a hypolipidemic agent because it inhibited lipogenesis and stimulated lipolysis by increasing UPC gene transcription. Because body fat development and adipocyte hypertrophy were suppressed, leptin secretion decreased. This hormone has a link with insulin in the long-term regulation of homeostasis energy (6), which could lead to a drop in carbohydrate absorption. Furthermore, Chen et al. (4) used a $\beta$ fructan, which is similar to levan but with a lower molecular weight (3.2 and $4.29 \mathrm{kDa})$, and observed a $70 \%$ reduction in plasma glucose in rats, the same reduction promoted by the control, Rosiglitazone (anti-diabetic-drug), used for these studies. Contrary to the literature, the levan utilized in this work did not present any of these effects.

Other published studies regarding the use of polymers composed of carbohydrates from plants $(27,33,34)$, fungi (12, $15,16,21)$, bacteria (8) and crustaceans $(17,31)$ as hypoglycemic and hypocholesterolemic agents obtained a series of positive results involving reductions in plasma glucose levels, which ranged between 20 and 70\%. Reductions in total plasma cholesterol levels that ranged between 20 and $80 \%$ and triacylglycerol level reductions that reached $38 \%$ were observed in mice and rats with diabetes induced by alloxan and STZ or in obese animals with hypercaloric diets.

\section{Analysis of weight gain, food intake and feed conversion efficiency (FCE)}

A higher food intake level and a decrease in feed conversion efficiency, in association with altered metabolic parameters, are factors that characterize the clinical symptoms of diabetes mellitus type I. Because $\beta$-cells can no longer produce insulin to uptake plasma glucose for further metabolism, the animals begin to lose weight (18). The analyses of weight gain, food intake and feed conversion efficiency were performed, and the results are shown in Table 2.

Table 2. Weight gain (g.day ${ }^{-1}$ ), average food intake (g.100 $\mathrm{g}^{-1}$ body weight per day) and feed conversion efficiency (FCE) of normal $(\mathrm{N})$, normal + levan $(\mathrm{N}+\mathrm{Lev})$, diabetic $(\mathrm{D})$ and diabetic + levan $(\mathrm{D}+\mathrm{Lev})$ rats after fifteen days.

\begin{tabular}{cccc}
\hline Groups & Body Weight Gain & Food Intake & Feed Conversion Efficiency (FCE) \\
\hline $\mathrm{N}$ & $5.28 \pm 6.08^{(\mathrm{a})}$ & $10.21 \pm 1.18^{(\mathrm{a})}$ & 0.52 \\
$\mathrm{~N}+$ Lev & $5.08 \pm 6.30^{(\mathrm{a})}$ & $10.60 \pm 1.24^{(\mathrm{a})}$ & 0.48 \\
$\mathrm{D}$ & $0.91 \pm 9.90^{(\mathrm{b})}$ & $18.27 \pm 2.32^{(\mathrm{b})}$ & 0.05 \\
$\mathrm{D}+$ Lev & $-0.40 \pm 8.67^{(\mathrm{b})}$ & $20.09 \pm 2.20^{(\mathrm{b})}$ & -0.02 \\
\hline
\end{tabular}

Values are expressed as the mean \pm S.D. $(\mathrm{n}=5)$. The dose of levan was $200 \mathrm{mg} \cdot \mathrm{kg}^{-1}$.

$\mathrm{a}, \mathrm{b}$ : Means with different letters within a column are significantly different $(\mathrm{p}<0.05)$. 
In accordance with the metabolic parameters, there was no statistical difference between the groups $(\mathrm{N})$ and $(\mathrm{N}+\mathrm{Lev})$ or between the groups (D) and (D+Lev) in weight gain, which represents one of the symptoms of clinical diabetes because the diabetic groups lost weight compared with the normal groups. Considering the means of food intake, once more, there was no difference observed between groups $(\mathrm{N})$ and $(\mathrm{N}+\mathrm{Lev})$, which was expected, but groups (D) and (D+Lev) were significantly different $(\mathrm{p}<0.05)$ from the normal groups; once these animals become diabetic, they are, generally, hyperphagic. The feed conversion efficiency was normal for both groups $(\mathrm{N})$ and $(\mathrm{N}+\mathrm{Lev})$, while for (D) and (D+Lev), the rate was extremely low and became negative for the group (D+Lev).

Yao et al. (31) demonstrated that chitosan had a hypoglycemic effect; however, the polymer did promote changes in the treatment animal's weight by the end of the experiment. However, Hwang et al. (12) and Miranda (21), using fungal polysaccharides, observed that in addition to the plasma glucose reduction, weight gain $(66 \%)$ and increased feed conversion efficiency (100\%) compared with control animals, the food intake of treatment animals approached that of the normal animals.

Factors that may have interfered in levan's action as a hypoglycemic agent

Molecular weight can be one of the factors that contributed to levan derived from $B$. subtilis Natto not inducing hypoglycemic, hypocholesterolemic or hypolipidemic effects. Whereas levan used in this work had a majority component (95\%) with a molecular weight equivalent to $72.37 \mathrm{kDa}$, Yamamoto et al. (30), Kang et al. (13) and Chen et al. (4) reported positive results that were achieved with a considerably higher $(2000 \mathrm{kDa})$ or lower (3.2 and $4.29 \mathrm{kDa})$ molecular weight compound. The degree of branching of levan may have also influenced the results because the microorganism used in this work, as well as the conditions for levan production, were different in relation to the earlier studies. The dosage used (200 mg. $\mathrm{kg}^{-1}$ body weight) is consistent with the published literature. Higher concentrations increase the viscosity of the solution, hindering levan application in the animals.

However, even without inducing the proposed effects, levan did not affect the bioenergetic metabolism of the animals, as no significant changes were observed between groups $(\mathrm{N})$ and $(\mathrm{N}+\mathrm{Lev})$ or between groups (D) and (D+Lev). This finding demonstrates the possibly that levan did not interfere with homeostasis in general, which raises the possibility for its use for other purposes.

Finally, it is important to note that of the animals that received levan, groups $(\mathrm{N}+\mathrm{Lev})$ and $(\mathrm{D}+\mathrm{Lev})$, behaved calmer and less aggressive when handled as opposed to members of groups (N) and (D), which emitted stress behaviors such as biting, scratching and grunting, especially the diabetics. It can be inferred that levan contributed to a change in the behavior of these animals, but specific studies are necessary to prove this observation.

\section{CONCLUSION}

The levan used in this work had no effect as a hypoglycemic agent because it did not provide any improvement in diabetic animals during the experiment. It did not affect the metabolism in general, which attests to its legitimacy as a non-toxic compound that can be used for other purposes. Moreover, it is important to consider the behavioral changes observed in rats given levan; however, specific studies are needed to confirm this observation.

\section{ACKNOWLEDGEMENTS}

The authors are grateful to Capes-Brazil for the financial support provided for this work and to the Neuroendocrine Laboratory of Physiology and Metabolism (LaFINeM) at the Department of Physiologic Sciences in the State University of Londrina (UEL).

\section{REFERENCES}

1. Bekers, M.; Laukevics, J.; Karsakevich, A.; Ventina, E.; Kaminska, E.; Upite, D.; Vina, I.; Linde, R.; Scherbaka, R. (2001). Levan-ethanol 
biosynthesis using Zymomonas mobilis cells immobilized by attachment and entrapment. Process Biochem. 36, 979-986.

2. Bolkent, S.; Yanardag, R.; Tabakoglu-Oguz, A.; Özsoy-Saçan, Ö. (2000). Effects of chard (Beta vulgaris L. var. cicla) extract on pancreatic B cells in streptozotocin-diabetic rats: a morphological and biochemical study. J. Ethnopharmacol. 73, 251-259.

3. Calazans, G.M.T.; Lima, R.C.; França, F.P.; Lopes, C.E. (2000). Molecular weight and antitumour activity of Zymomonas mobilis levans. Int. J. Biol. Macromol. 27, 245-247.

4. Chen, X.; Liu, Y.; Bai, X.; Wen, L.; Fang, J.; Ye, M.; Chen, J. (2009). Hypoglycemic polysaccharides from the tuberous root of Liriope spicata. J. Nat. Prod. 72, 1988-1992.

5. Cho, E.J.; Hwang, H.J; Kim, S.W.; Oh, J.Y.; Baek, Y.M.; Choi, J.W.; Bae, S.H.; Yun, J.W. (2007). Hypoglycemic effects of exopolysaccharides produced by mycelia cultures of two different mushrooms Tremella fuciformis e Phellinus baumii in ob/ob mice. Appl. Microbiol. Biotechnol. 75, 1257-1265.

6. Dagogo, J.S.; Fanelli, C.; Parmore, D.; Brother, J.; Landt, M. (1996). Plasma leptin and insulin relationship in obese and nonobese humans. Diabetes. 45, 695-698.

7. Doelle, H.W.; Kirk, L.; Crittenden, R.; Toh, H.; Doelle, M.B. (1993). Zymomonas mobilis: science and industrial application. Crit. Rev. Biotechnol. 13, 57-98.

8. El-Gawad, I.A.A.; El-Sayed, E.M.; Hafez, S.A.; El-Zeini, H.M.; Saleh, F.A. (2005). The hypocholesterolaemic effect of milk yoghurt and soyyoghurt containing bifiodobacteria in rats fed on a cholesterol-enriched diet. Int. Dairy J. 15, 37-44.

9. Euzenat, O.; Guibert, A.; Combes, D. (1997). Production of fructo oligosaccharides by levansucrase from Bacillus subtilis C4. Process Biochem. 32 (3), 237-243.

10. Gupta, S.K.; Pal, A.K.; Sahu, N.P.; Dalvi, R.; Kumar, V.; Mukherjee, S.C. (2008). Microbial levan in the diet of Labeo rohita Hamilton juveniles: effect on non-specific immunity and histopathological changes after challenge with Aeromonas hydrophila. J. Fish Dis. 31, 649-657.

11. Han, Y.W.; Clarke, M.A. (1990) Production and characterization of microbial levan. J. Agric. Food Chem. 38, 393-396.

12. Hwang, H.J.; Kim, S.W.; Lim, J.M.; Joo, J.H.; Kim, H.O.; Kim, H.M.; Yun, J.W. (2005). Hypoglycemic effect of crude exopolysaccharides produced by a medicinal mushroom Phellinus baumii in streptozotocininduced diabetic rats. Life Sci. 76, 3069-3080.

13. Kang, S.A.; Hong, K.; Jang, K.H.; Kim, Y.Y.; Choue, R.; Lim, Y. (2006). Altered mRNA expression of hepatic lipogenic enzyme and PPAR alpha in rats fed dietary levan from Zymomonas mobilis. J. Nutr. Biochem.17, 419-426.

14. Kuzuya, T.; Nakagawa, S.; Satoh, J.; Kanazawa, Y.; Iwamoto,Y.; Kobayashi, M.; Nanjo, K.; Sasaki, A.; Seino, Y.; Ito, C.; Shima, K.; Nonaka, K.; Kadowaki, T. (2002). Report of the Committee on the classification and diagnostic criteria of diabetes mellitus. Diabetes Res. Clin. Pract. 55, 65-85.

15. Li, S.P.; Zhang, G.H.; Zeng, Q.; Huang, Z.G.; Wang, Y.T.; Dong, T.T.X.; Tsim, K.W.K. (2006). Hypoglycemic activity of polysaccharide, with antioxidation, isolated from cultured Cordyceps mycelia. Phytomedicine. 13, 428-433.

16. Li, H.; Zhang, M.; Ma, G. (2010). Hypolipidemic effect of the polysaccharide from Pholiota nameko. Nutr. 26, 556-562.

17. Liu, J.; Zhang, J.; Xia, W. (2008). Hypocholesterolaemic effects of different chitosan samples in vitro and in vivo. Food Chem. 107, 419425.

18. Luo, Q.; Cai, Y.; Yan, J.; Sun, M.; Corke, H. (2004). Hypoglycemic and hypolipidemic effects and antioxidant activity of fruit extracts from Lycium barbarum. Life Sci. 76, 137-149.

19. Melo, I.R.; Pimentel, M.F.; Lopes, C.E.; Calazans, G.M.T. (2007). Application of fractional factorial design to levan production by Zymomonas mobilis. Bras. J. Microbiol. 38, 45-51.

20. Meng, G.; Fütterer, K. (2003). Sctrutural framework of fructosyl transfer in Bacillus subtilis levansucrase. Nat. Struct. Biol. 10, 953-941.

21. Miranda, C.C.B.O. (2006). Produção de botriosferana e avaliação de suas atividades mutagênica, antimutagênica, hipoglicemiante e hipocolesterolêmica. Londrina, Brasil, 185p. (M.Sc. Dissertation. Departamento de Bioquímica e Biotecnologia. UEL).

22. Oliveira, M.R.; Silva, R.S.S.F.; Buzato, J.B.; Celligoi, M.A.P.C. (2007). Study of levan production by Zymomonas mobilis using regional lowcost carbohydrate sources. Biochem. Eng. J. 37, 177-183.

23. Ryan, K.J.; Ray, C.G. (2004). Sherris Medical Microbiology, $4^{\text {th }}$ ed. McGraw Hill, New York.

24. Shih, I.L.; Yu, Y.T.; Shieh, C.J.; Hsieh, C.Y. (2005). Selective Production and Characterization of Levan by Bacillus subtilis (Natto) Takahashi. J. Agric. Food Chem. 53, 8211-8215.

25. Shih, I.L.; Chen, L.D.; Wu, J.Y. (2010). Levan production using Bacillus subtilis natto cells immobilized on alginate. Carbohydr. Polym. 82, 111117.

26. Shu, C.H.; Lung, M.Y. (2004). Effect of $\mathrm{pH}$ on the production and molecular weight distribution of exopolisaccharides by Antrodia camphorata in batch cultures. Process Biochem. 39, 931-937.

27. Tong, H.; Liang, Z.; Wang, G. (2008). Structural characterization and hypoglycemic activity of a polysaccharide isolated from the fruit of Physalis alkekengi L. Carbohydr. Polym. 71, 316-323.

28. Tzang, B.S.; Yang, S.F.; Fu, S.G.; Yang, H.G.; Sun, H.L.; Chen, Y.C. (2009). Effects of dietary flaxseed oil on cholesterol metabolism of hamsters. Food Chem. 114, 1450 -1455.

29. World Health Organization. 2011. Media centre: Diabetes. Available at: http://www.who.int/mediacentre/factsheets/fs312/en/index.html. Acessed 10 June 2011.

30. Yamamoto, Y.; TakahashI, Y.; Kawano, M.; Iizuka, M.; Matsumoto, T.; 
Saeki, S.; Yamaguchi, H. (1999). In vitro digestibility and fermentability of levan and its hypocholesterolemic effects in rats. $J$. Nutr. Biochem. 10, 13-18.

31. Yao, H.T.; Huang, S.Y.; Chiang, M.T. (2008). A comparative study on hypoglycemic and hypocholesterolemic effects of high and low molecular weight chitosan in streptozotocin-induced diabetic rats. Food Chem. Toxicol. 46, 1525-1534.

32. Yoo, S.H.; Yoon, E.J.; Cha, J.; Lee, H.G. (2004). Antitumor activity of levan polysaccharides from selected microorganisms. Int.l J. Biol.
Macromol. 34, 37-41.

33. Zhang, R.; Zhou, J.; Jia, Z.; Zhang, Y.; Gu, G. (2004). Hypoglycemic effect of Rehmannia glutinosa oligosaccharide in hyperglycemic and alloxan-induced diabetic rats and its mechanism. J. Ethnopharmacol. 90, 39-43.

34. Zou, S.; Zhang, X.; Yao, W.; Niu, Y.; Gao, X. (2010). Structure characterization and hypoglycemic activity of a polysaccharide isolated from the fruit of Lycium barbarum. Carbohydr. Polym. 80, 1161-1167. 